\title{
Pathogenesis of HIV-Related Organ/Tissue Disorder
}

National Cancer Institute

\section{Source}

National Cancer Institute. Pathogenesis of HIV-Related Organ/Tissue Disorder. NCI

Thesaurus. Code C18926.

Induction or development of an organ or tissue disorder(s) that results from retroviral activity or arises due to the immunocompromised state of an HIV infected individual. $(\mathrm{NCl})$ 